\title{
QoS Comparison of MANET Routing Protocols
}

\author{
Tarunpreet Bhatia and A.K. Verma \\ Department of Computer Science Engineering, Thapar University, Patiala - 147004, India \\ Email: tarunpreetbhatia@gmail.com,akverma@thapar.edu
}

\begin{abstract}
The primary concern for the deployment of MANET is to promote flexibility, mobility and portability. This mobility causes dynamic change in topology and poses challenges for designing routing algorithms. In the past few years, many ad hoc network protocols have been developed and research is still going on. It becomes quite difficult to say which protocols may perform well under different network scenarios such as varying network size, mobility of nodes and network load etc. This paper analyzes the performance of proactive protocols like DSDV, OSLR, reactive protocols like AODV, DSR and hybrid protocol such as ZRP. The analysis guides us to the evaluation of various performance metrics such as throughput, packet delivery fraction, normalized routing load and average end to end delay under different scenarios such as varying network size, speed of the node and pause time. The focus of this paper is to have quantitative analysis to guide which protocol to choose for specified network and goal.
\end{abstract}

Index Terms-Mobile Adhoc Networks (MANET), Routing Protocols, QoS, AODV, DSR, DSDV, OLSR, ZRP.

\section{INTRODUCTION}

MANET is a self configured network consisting of mobile nodes connecting by wireless links forming an arbitrary topology. Mobile nodes are free to move randomly in any direction with any speed so network topology often changes. Adhoc network is a multihop wireless network in which nodes work in collaboration with each other to transmit data packets. Information is transmitted from source to destination via intermediate nodes so every node in a network acts as a host and router. As the nodes move outside the communication range of other nodes, the resulting change in topology must be propagated to other nodes so that network topology information must be updated.

Routing is the process of selecting path in a network along which logically addressed packets are sent from source node to their ultimate destination node through intermediate nodes. Basically routing involves two components- Optimal routing path determination and transferring the packets through the established path in an internetwork. The transferring process is straight forward but optimal path determination is a complex issue. A routing protocol is designed to specify how mobile nodes should communicate with each other to disseminate information. Routing protocols use several metrics like path length, reliability, routing delay, bandwidth, load, communication costs etc to evaluate the best routing path out of several alternatives for routing data packets. The routing process directs forwarding of packets on the basis of routing table in which entries are keyed by the destinations. Desirable properties of ad-hoc routing protocols [1]

- Distributed operation: The protocol must operate in distributed manner instead of relying on centralized node as nodes may leave and enter the network at any time.

- Demand based routing: The routing protocol should react only when route is needed. It should not consume network resources by flooding the network with periodically broadcasting control messages.

- Loop free routing: In order to prevent misuse of bandwidth or CPU power routes supplied must be loop-free.

- Multiple routes: Routing protocol must find multiple routes to destination so that if one route becomes invalid other can be used without initiating another route discovery.

- Power conservation: Routing protocol should support sleeping modes because mobile nodes are limited in battery power.

- Quality of service: Based on the applications of MANET, some sort of QoS support is needed in routing protocol so that route is found with less overhead.

Mobile ad-hoc routing protocols are divided into following categories [2]:

- Proactive protocols in which each node has to maintain up-to-date information about all other nodes within an ad hoc network in its routing table.

- Reactive protocols in which routes are created on demand. Whenever a node wants to send data it initiates route discovery.

- Hybrid routing protocols which is combination of above two. Within a small domain proactive is used and among domains reactive approach is used.

This paper presents an overview of various routing protocols emphasizing their pros and cons, applicability in different situations based on their performance. Section 3 revisits operation of proactive, reactive and hybrid protocols. Section 4 presents performance metrics chosen and Section 5 discusses simulation environment and then 
the results are analyzed. Finally Section 6 summarizes the results.

Table 1. Classification of Routing Protocols

\begin{tabular}{|c|c|c|c|}
\hline Parameters & Reactive protocol & Proactive protocol & Hybrid protocol \\
\hline Routing scheme & On demand routing & Table driven routing & Combination of both \\
\hline $\begin{array}{l}\text { Resource } \\
\text { consumption }\end{array}$ & $\begin{array}{l}\text { Resource consumption and } \\
\text { overhead is low due to minimum } \\
\text { exchange of control information }\end{array}$ & $\begin{array}{l}\text { They consume significant network } \\
\text { resources and incur substantial } \\
\text { traffic that is scarce in ad-hoc } \\
\text { network. }\end{array}$ & $\begin{array}{l}\text { Inside zone resource consumption is } \\
\text { more outside zone is less. }\end{array}$ \\
\hline Scalability level & $\begin{array}{l}\text { Not suitable for large } \\
\text { Networks. Supports approximately } \\
100-200 \text { nodes }\end{array}$ & $\begin{array}{l}\text { Suitable for small networks i.e. less } \\
\text { than } 100 \text { nodes }\end{array}$ & $\begin{array}{l}\text { Designed for large networks for nodes } \\
\text { greater than } 1000\end{array}$ \\
\hline Route discovery & $\begin{array}{l}\text { Only the source node initiates route } \\
\text { discovery whenever it has to send } \\
\text { data. }\end{array}$ & $\begin{array}{l}\text { Route has to be maintained by every } \\
\text { node so all the nodes initiate route } \\
\text { discovery. }\end{array}$ & $\begin{array}{l}\text { Each node inside a zone initiates route } \\
\text { discovery. }\end{array}$ \\
\hline $\begin{array}{l}\text { Availability of } \\
\text { routing information }\end{array}$ & Available when required & $\begin{array}{l}\text { Route is maintained between each } \\
\text { host pair at all the times and stored } \\
\text { in routing tables. }\end{array}$ & Combination of both \\
\hline Periodic updates & $\begin{array}{l}\text { Periodic updates are not sent as } \\
\text { control information is not required } \\
\text { until the topology changes. }\end{array}$ & $\begin{array}{l}\text { The constant propagation is done } \\
\text { periodically even when topology is } \\
\text { not changed. }\end{array}$ & $\begin{array}{l}\text { Periodic updates are needed inside the } \\
\text { zone even if topology doesn't changes. }\end{array}$ \\
\hline Storage capacity & $\begin{array}{l}\text { Low generally depends upon the } \\
\text { number of routes. }\end{array}$ & High due to the routing tables & $\begin{array}{l}\text { Depends on the size of Zone, inside the } \\
\text { zone sometimes high. }\end{array}$ \\
\hline Merit & $\begin{array}{l}\text { Path available when } \\
\text { needed overhead is } \\
\text { low and free from } \\
\text { loops. }\end{array}$ & $\begin{array}{l}\text { Information is always available. } \\
\text { Latency is low in the network }\end{array}$ & $\begin{array}{l}\text { Suitable for large networks and up to } \\
\text { date information is available for routing } \\
\text { inside the zone so latency is low. }\end{array}$ \\
\hline Demerit & $\begin{array}{l}\text { Latency is increased in the network } \\
\text { due to flooding of route requests }\end{array}$ & $\begin{array}{l}\text { Overhead is high; Routing } \\
\text { information is flooded in the whole } \\
\text { network. }\end{array}$ & Complexity increases \\
\hline Examples & $\begin{array}{l}\text { AODV, DSR, TORA, AOMDV, } \\
\text { STAR, GPSR }\end{array}$ & $\begin{array}{l}\text { DSDV, OLSR, FSR, CGSR, WRP, } \\
\text { GSR }\end{array}$ & ZRP, CEDAR, ZHLS,LAR \\
\hline
\end{tabular}

\section{RELATED WORK}

In the literature, various routing protocols have been compared using different parameters. In [3], authors presented the comparative study of three mobile ad hoc routing protocols (OLSR, AODV and TORA). The quantitative study of these routing protocols showed that OLSR is more competent in high density networks with highly sporadic traffic. AODV keeps on improving in packet delivery ratio with dense networks. TORA performs much better in packet delivery owing to selection of better routes using acyclic graph for dense networks.

In [4], authors compared the performance of AODV, OLSR, TORA, DSR and DSDV under two different scenarios i.e. mobility and traffic but characterized it as high and low instead of actual values of mobility and traffic. In [5], authors compared AODV, DSR, CBRP and DSDV on the basis of network mobility taking fixed number of nodes as 5. They concluded that AODV always performs better than DSR, DSDV and CBRP in terms of throughput and average delay while CBRP is better in terms of packet delivery ratio.

In [6], authors presented the performance analysis of DSR, AODV and CGSR in MANET based on energy consumption using OMNeT++4.3 considering different mobility and traffic models. In [7], authors simulated AODV, OLSR, DSDV for small network with nodes varying from 5 to 15 . They concluded that OLSR protocol gives best results in terms of packet delivery ratio, packet dropped, jitter and end to end delay. In case of throughput, the performance of AODV protocol is far better than others.

This paper does an extensive and comprehensive performance evaluation of protocols from each category: proactive, reactive and hybrid with varying scalability, mobility and pause time.

\section{OVERVIEW OF MANET ROUTING PROTOCOLS}

\section{A. $D S D V$}

Perkins et al [8] proposed destination sequence distance vector routing protocol based on the traditional Bellman Ford algorithm with some improvements to prevent count to infinity problem. Each node maintains routing table having entries corresponding to all other nodes in the network. Each node maintains a set of distances to reach destination via its neighbors and chooses the neighbor as next hop having minimum distance for packet delivery to that destination. It is a proactive protocol so the nodes periodically transmit their routing tables to their immediate neighbors or whenever change in topology occurs. While sending an update message, a node has to increment its sequence number. Whenever a node receives a broadcasted routing message from its neighborhood, it compares received message's sequence number and hop count fields with the corresponding value stored in its routing table and 
updates its routing table depending on larger sequence number and smaller hop count by re-computing the distances. DSDV responds to RERR messages by invalidating all routes in their routing table containing broken link. These routes are immediately assigned an infinite metric and an incremented sequence number.

Merits

- Route discovery latency is very low as route is always available.

- Generates loop-free paths and count to infinity problem of distance vector routing is also removed.

- Extra traffic can be avoided using incremental update strategy than sending full updates.

Demerits

- Wastage of bandwidth and large amount of network overhead while transmitting periodic route update messages. So, DSDV does not scale well in large and dense networks.

- It doesn't support multipath routing since single path to destination is maintained.

\section{B. $O L S R$}

Optimized Link State routing $[9,10]$ is a proactive routing protocol that inherits stability of classical link state routing and modifying it to reduce the overhead of flooding and size of link state update messages. The key feature is the use of selected nodes called Multipoint Relays (MPR) from its neighbors to retransmit control messages to minimize flooding overhead. MPR set of a node is selected from its one hop neighbors such that a message broadcasted by a source node after retransmission by MPR set covers all the nodes having two hop distances from it. Other neighbors can process the message without rebroadcasting thus reducing number of retransmissions involved in flooding entire network with that message. Periodic Hello messages containing a list of all the neighbors are exchanged among nodes to learn about their two hop neighbors using some algorithm [11]. OLSR being a proactive protocol maintains a route to every other node in a network. MPRs are responsible for forwarding control traffic. Topology control TC messages listing set of neighbors that selected sending node as MPR are exchanged with neighbors to diffuse topology information. This set of MPR nodes is advertised within the network. Nodes receiving TC messages create or modify their routing table entries using any shortest path algorithm like Dijkstra algorithm.

\section{Merits}

- OLSR is distributed protocol so no central administration to handle the routing process.

- The link is reliable since the update messages are sent periodically.

- OLSR works well with for large and high density networks as optimization is done by using MPRs.

- Routes are always available so no route discovery delays for finding a route.
Demerits

- OLSR protocol periodically sends the updated topology information throughout the entire network.

- OLSR requires a reasonably large amount of bandwidth and CPU power for computing optimal routing paths in the network.

- In case of packet loss in the network, some nodes that are not part of MPR set may start retransmitting the packets.

\section{C. $A O D V$}

Adhoc On Demand Distance Vector [12] is an improvement over DSDV because it minimizes number of broadcasts by creating routes on demand opposed to DSDV that maintains a complete list of routes. It maintains one entry per destination in its routing table and ensures hop by hop and loop free routing through the use of sequence numbers. HELLO messages are used to obtain neighborhood connectivity. A mobile node broadcasts route discovery message to its neighbors whenever it has to send data and does not have route to that destination in its routing table. As RREQ propagates through the networks, intermediate nodes update their routing table in reverse direction to the source node using it. Route reply is generated by either destination node or some intermediate node having unexpired route to destination. Lifetime is associated with each routing table entry that prevents stale routes. As route reply is unicasted back to the source node along the path set while forwarding RREQ, intermediate nodes lying on this path update their routing table entries in the direction of destination node. A node sending a new update message has to increment its own sequence number. Higher sequence number signifies fresher route. Each intermediate node stores most recent sequence number of every node and updates its routing table entry whenever a packet with higher sequence number is received [13]. The route between source and destination is maintained till source needs that route. In case any node moves during this time interval, RREQ messages are generated and forwarded to source node. Then source node initiates fresh route discovery. AODV has route maintenance phase for handling broken links. Source node rebroadcasts query messages if no reply is received after a timeout.

Merits

- Less overhead as routes are created on demand and less flooding of updates.

- Packet size is constant

- Latency is constant with increased mobility of nodes provided concentration of nodes should remain similar.

- Minimal space complexities as stale routes are deleted.

\section{Demerits}

- Multiple reply packets sent for single route request message increases network overhead.

- Intermediate nodes have higher sequence numbers 
not necessarily latest which can leads to inconsistent and stale routes.

- Periodic Hello messages leads to unnecessary bandwidth consumption.

\section{DSR}

Dynamic Source Routing Protocol [14] is a very basic and an efficient on demand protocol for routing in mobile adhoc and wireless networks designed to eliminate periodic update messages required in proactive protocols. It follows source routing in which source node determines the complete sequence of nodes through which routing packet travels. Each node maintains routing cache for storing list of routes learned in the past and can store multiple routes to a destination. Route Request is uniquely identified by (source address, request id) pair to prevent forwarding of duplicate RREQs to ensure loop free routing. The protocol operates in two phases- Route discovery initiated when route to destination is not available in route cache. Intermediate nodes receiving non-duplicate RREQ can either reply back if it has unexpired route in its cache after attaching their own address or rebroadcasts RREQ to their neighbors. Target node returns RREP back to source node using the path if present in the route cache or following the reverse route entries made during forward propagation of RREQ. Route error messages are sent to source node. In case any node detects any link failure with its next hop. All the intermediate nodes remove the routes containing that hop from their route cache. The source node can either choose alternating path or initiate new route discovery phase [15].

\section{Merits}

- Reduced overhead as routes are maintained for nodes that want to communicate.

- A node reacts quickly to changes in topology

- No beacon messages are exchanged so effective usage of bandwidth can be done.

\section{Demerits}

- Stale route cache entries may result in inconsistencies.

- Broken links are not repaired locally.

- Not scalable to network size as packet header increases with increasing number of hops in a route.

\section{E. $Z R P$}

(Zone Routing Protocol): Haas et. al [16] proposed zone routing protocol which is a hybrid protocol incorporating merits of both proactive routing protocols within local neighborhood and reactive routing protocol for communication across the network between these neighborhoods. In ZRP, each node proactively maintains routes to other nodes within its local neighborhood having hop distance within zone radius range chosen as a parameter. This leads to the partitioning of the network into overlapping and variable-sized routing zones. It is composed of locally proactive routing part IARP (Intrazone Routing Protocol) and globally routing part
IERP (Interzone Routing Protocol). Nodes within the zone are interior nodes, at the boundary of zone are peripheral nodes and all other are exterior nodes. Source node that wishes to send data to a particular destination initiates route discovery message. If destination lies within routing zone of source, route is already available and routing is completed in intrazone phase otherwise packet is sent to peripheral nodes through border casting. Each node appends its address to RREQ. RREQ message is re-border casted till it reaches a node having destination lying in its routing zone. That node immediately initiates route reply message that is forwarded back to source node. Route maintenance for broken links is always done locally inside a routing zone. An important issue of zone routing protocol is to determine the optimum size of the zone. P. Samar et al proposed an enhanced zone routing protocol, Independent Zone Routing (IZR) that provides an adaptive and distributed reconfiguration of the size of zone enhancing the scalability of the ad hoc network [17].

\section{Merits}

- No single point of failure.

- Improved reliability and performance i.e. less delay and less control overhead.

- Border Resolution Protocol avoids flooding in the network as route requests are passed to border nodes

- ZRP scales well for large networks having diverse mobility patterns.

- Ensures loop free routing and multiple routes to destination are found.

Demerits

- Power is issued for sending packet without considering position of source and destination nodes so it is wasted if they are too close because power received by the destination node is always inversely proportional to the square of the distance between the nodes.

- If the distance between source and destination is more, zone area increases which leads to more number of bordercasts to find border zone increasing bandwidth utilization.

- Selecting a zone radius regularly is a critical issue as performance of ZRP depends on it.

\section{PERFormanCE METRICS}

Quantitative measures chosen to evaluate MANET routing protocols are as follows:

\section{A. Throughput}

Throughput signifies data packets received at the destination in some period of time [18].

$$
\text { Average Throughput }=\frac{\text { Databytes received } X 8}{\text { Simulation Time } X 1000}
$$




\section{B. Packet delivery fraction (PDF)}

PDF signifies the ratio of the data packets delivered to the destination successfully to those generated by the source nodes [19].

$$
P D F=\frac{\text { Packets received by destination }}{\text { Packets sent by source }} X 100
$$

\section{Normalize Routing Load (NRL)}

It is the number of routing packets transmitted within the network per data packets [19].

$$
N R L=\frac{\text { Number of routing packets transmitted }}{\text { Total number of packets received }}
$$

\section{Average end-to-end delay (average E2E delay)}

Average End-to-End [20] delay is the average time taken to transmit a data packet across a MANET from source to destination. It includes not only propagation and transfer time of data packets but also other delays like buffering during the route discovery phase, waiting at the interface queue, retransmission time at the MAC (Medium Access Control). The average end-to-end delay can be calculated by summing the times taken by all received packets divided by their total numbers. The Average End-to-End Delay should be less for high performance.

$$
\text { E2E delay }=\frac{\sum_{\text {packetid }=1}^{N} \operatorname{Re} \text { ceived } \text { packetid }- \text { Sent }_{\text {packetid }}}{N}
$$

where $\mathrm{N}$ is the number of data packets successfully

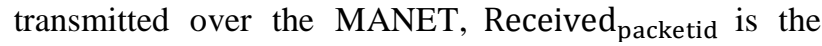
time at which a packet is received and Sent ${ }_{\text {packetid }}$ is the time at which a packet with is sent.

\section{Simulation ENVIRONMENT AND RESUlts}

The simulations were performed using NS-2 simulator [22]. Network traffic is generated using CBR (Constant Bit Rate) [23]. Each CBR source sends UDP packets at the rate of 0.25 i.e. 4 packets per second and each packet is of constant size 512 bytes without waiting for acknowledgments so number of packets sent and received are counted separately. Each node maintains an interface DropTail/PriQueue of maximum size 50. The Random Waypoint Mobility Model [18] is used within a square field of 750 by 750 . In this model, a mobile node has to stay at one location for a certain amount of time. After expiration of that time, the mobile node randomly moves to a point within the simulation area with a speed uniformly distributed between minspeed and maxspeed. Simulation time is $100 \mathrm{sec}$ and maximum number of connections is 30. Simulation model chosen is TwoRayGround and MAC type is 802.11. Other parameters are listed in Table 2.

Table 2. Varying Simulation Parameters

\begin{tabular}{|l|c|c|c|}
\hline Parameter & Scenario 1 & Scenario 2 & Scenario 3 \\
\hline Speed $(\mathrm{m} / \mathrm{s})$ & $\begin{array}{c}5,10,20,30, \\
50\end{array}$ & 10 & 5 \\
\hline $\begin{array}{l}\text { Number of } \\
\text { nodes }\end{array}$ & 20 & $\begin{array}{c}20,40,60, \\
80,100\end{array}$ & 20 \\
\hline $\begin{array}{l}\text { Pause Time } \\
(\mathrm{sec})\end{array}$ & 5 & 2 & $5,10,20,40,80$ \\
\hline
\end{tabular}

\section{A. Effect of varying speed on MANET routing protocols}

Speed of mobile nodes has direct effect on various performance metrics like NRL, PDF etc in a mobile adhoc networks. In this scenario, speed changes from $5 \mathrm{~m} / \mathrm{s}$ to $50 \mathrm{~m} / \mathrm{s}$ with pause time $10 \mathrm{sec}$ and number of nodes 20. Throughput of a node decreases as speed of a node increases as shown in Fig. 1. With low mobility all protocols behave almost same but as speed increases degradation in the performance of DSDV is most and throughput reduces by $56 \%$. AODV and DSR have better output with an average throughput of $119.29 \mathrm{kbps}$ and $121.47 \mathrm{kbps}$ respectively. ZRP has relatively high throughput than DSDV.

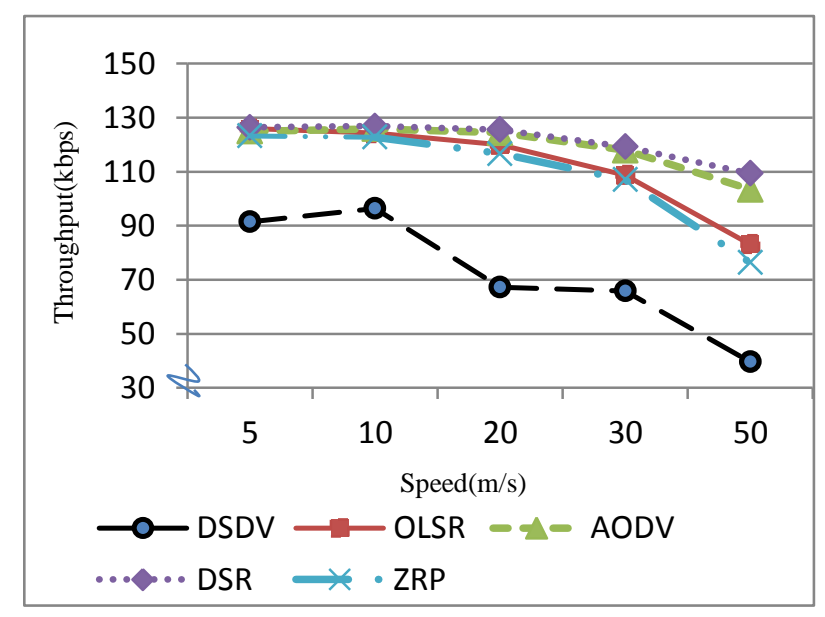

Fig.1. Throughput vs Speed

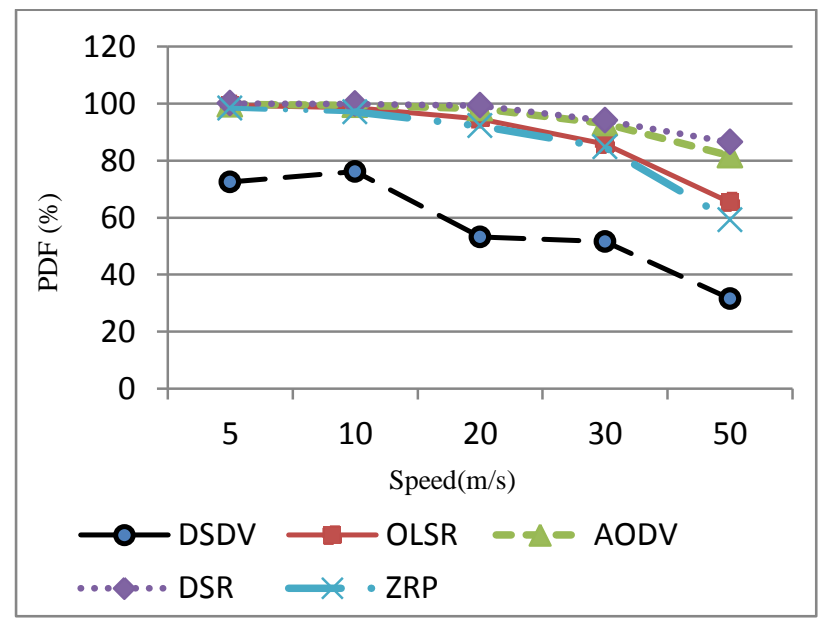

Fig.2. PDF vs Speed 
Fig. 2 shows that packet delivery fraction decreases as speed of a node increases. In terms of PDF, DSR is the best protocol and DSDV exhibits worst behavior for smaller networks with number of nodes 20. PDF of OLSR and ZRP decreased to about $38.83 \%$ as speed is increased from $5 \mathrm{~m} / \mathrm{s}$ to $50 \mathrm{~m} / \mathrm{s}$ but for AODV and DSR decrease percentage is just $17.96 \%$ and $13.59 \%$ respectively. PDF of ZRP, DSDV and OLSR is lower than AODV and DSR. Minimum PDF for DSDV is $31.52 \%$ and maximum $72.43 \%$ whereas for DSR is maximum $99.97 \%$ and minimum $86.40 \%$. AODV has slightly less PDF than DSR because of high packet drop rates due to route expiry.

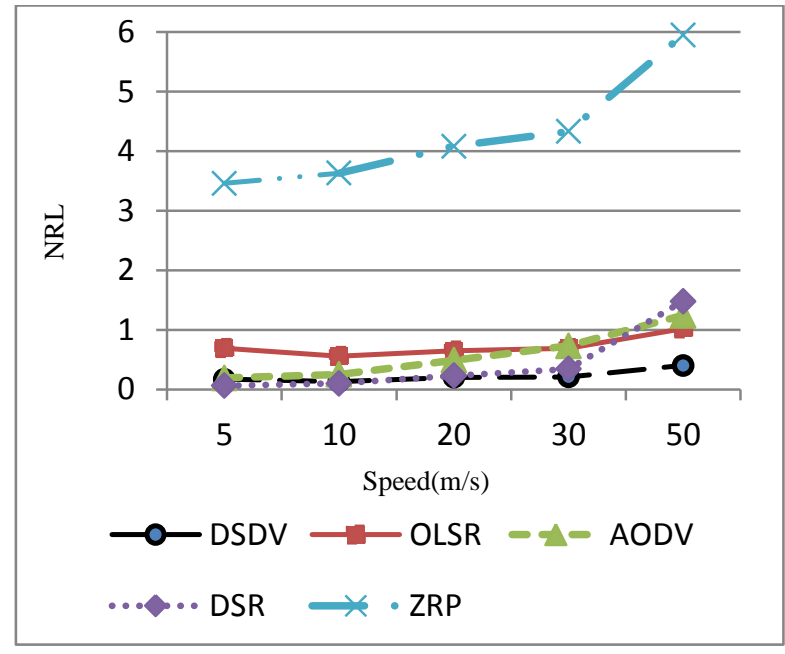

Fig.3. NRL vs Speed

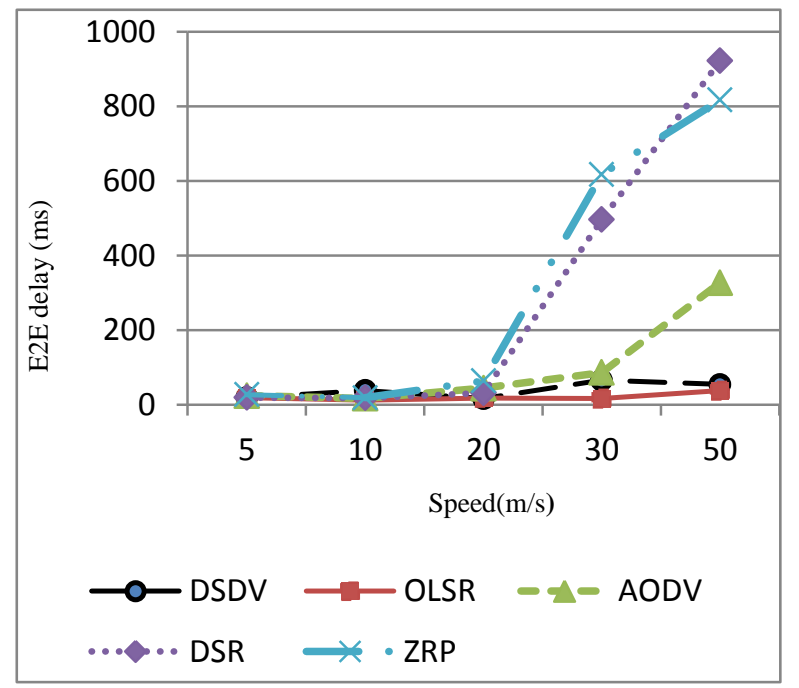

Fig.4. E2E delay vs Speed

Table 3. Numerical comparison of Routing Protocols in terms of speed

\begin{tabular}{|l|c|c|c|c|c|}
\hline & DSDV & OLSR & AODV & DSR & ZRP \\
\hline Throughput & 5 & 3 & 1 & 2 & 4 \\
\hline PDF & 5 & 3 & 2 & 1 & 4 \\
\hline NRL & 1 & 4 & 3 & 2 & 5 \\
\hline E2E Delay & 2 & 1 & 2 & 4 & 5 \\
\hline
\end{tabular}

\section{B. Effect of number of nodes}

Varying number of nodes has a major effect on the network parameters. Fig. 5 depicts the variation in throughput by increasing number of nodes. On an average throughput decreases as network density increases due to congestion and collision in the networks. When the network size is moderate i.e 40 nodes, the topology is quiet dense and the network connectivity is high so throughput increases slightly. Further increasing nodes deteriorates throughput which goes to $11.89 \mathrm{kbps}$ from $119.38 \mathrm{kbps}$ in ZRP and $171.52 \mathrm{kbps}$ to $125.22 \mathrm{kbps}$ in AODV with 100 nodes. The comparatively low throughput of DSR is due to aggressive route caching. OLSR has high throughput of $128.83 \mathrm{kbps}$ with 100 nodes.

PDF decreases with increasing number of nodes as congestion in network increases resulting in more dropped packets due to collisions refer Fig. 6. For smaller networks i.e. 20 nodes, DSR has highest PDF $99.87 \%$ among all other protocols. But with increasing number of nodes AODV outperforms DSR. AODV maintains almost steady PDF OF $86 \%$ in different network sizes. ZRP shows highest fluctuation with network size. PDF drops from $94 \%$ to $75 \%$ with 40 nodes which further reduces to $6.75 \%$ in a network with 100 nodes. AODV has almost OLSR shows the second best performance with an average PDF of $84.67 \%$. There is very little effect on PDF of DSDV with increasing network size having an average value of $54.18 \%$. Its PDF rises to $68.46 \%$ with 40 nodes from initial value $53.81 \%$ with 20 nodes and afterwards starts decreasing.

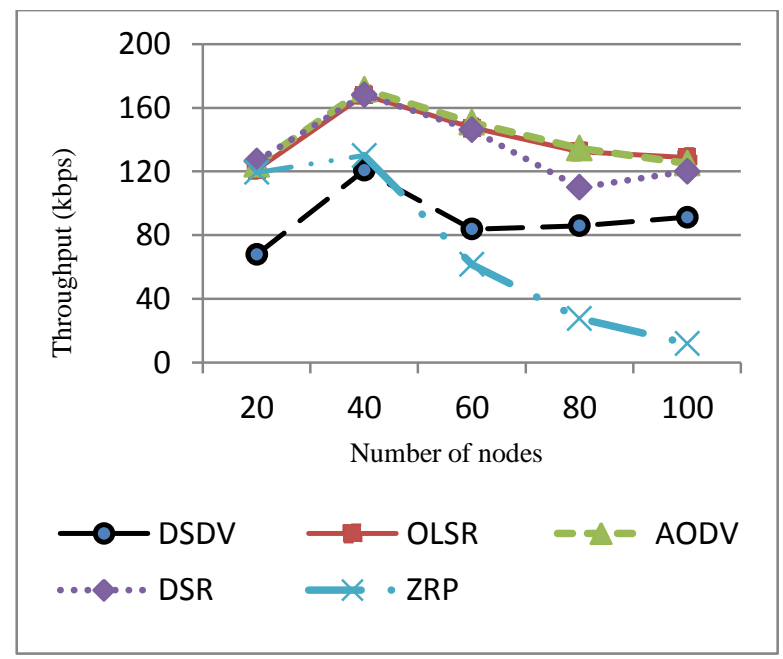

Fig.5. Throughput vs Number of nodes

NRL increases as number of nodes in a network increases because of increasing neighborhood more routing packets are exchanged as shown in Fig. 7. It is quiet visible from Fig. 7 that DSDV has least NRL and it is fairly stable with increasing network size. 


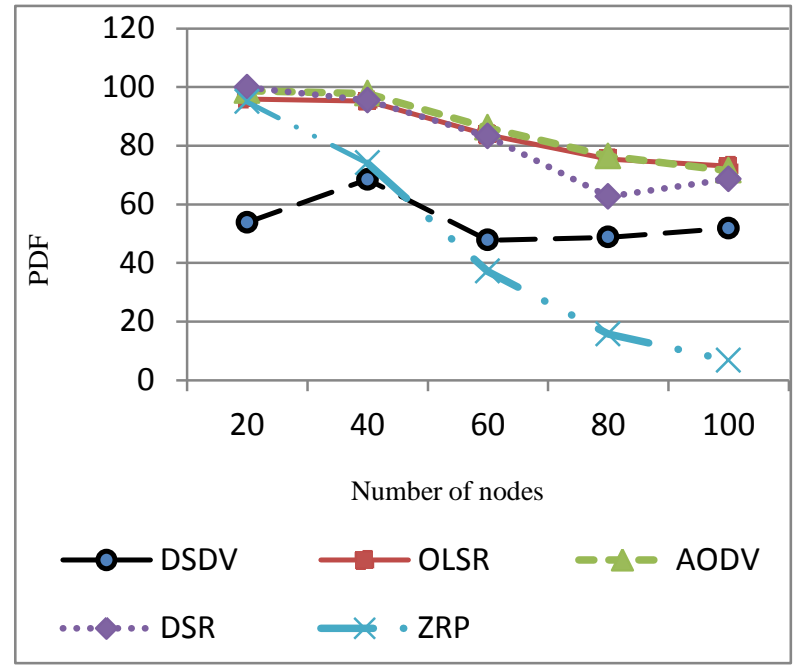

Fig.6. PDF vs Number of nodes

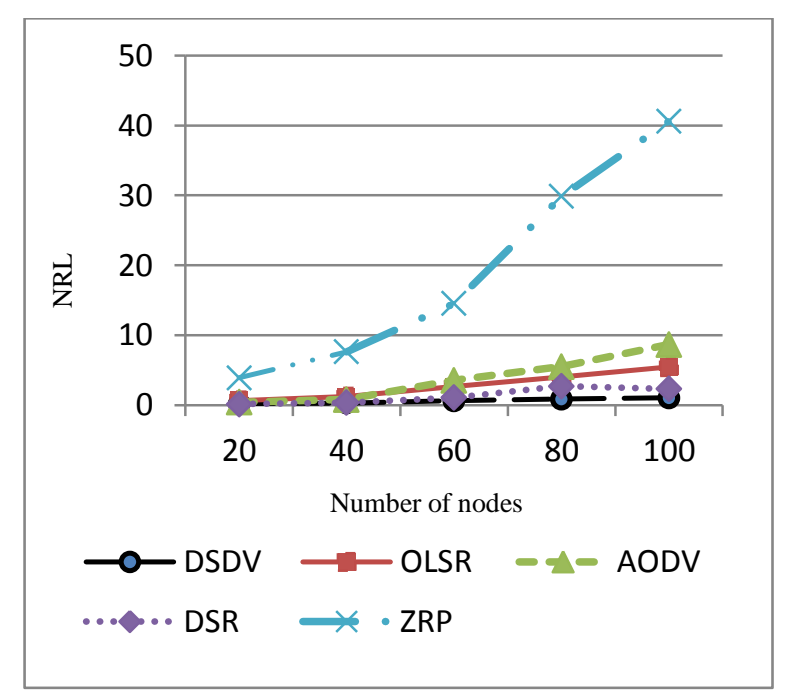

Fig.7. NRL vs Number of nodes

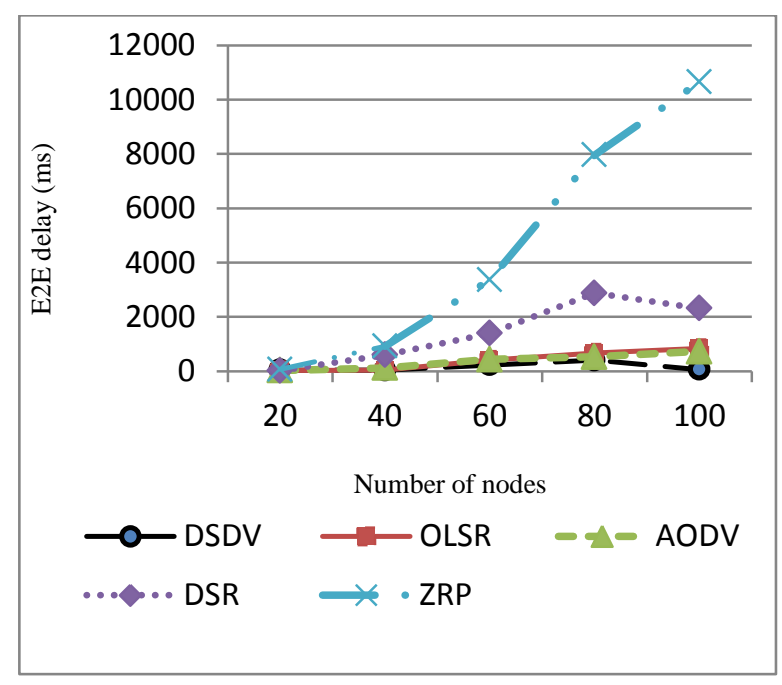

Fig.8. E2E delay vs Number of nodes

A stable routing overhead is a desirable property for scalability of routing protocols. DSR has relatively low routing overhead than AODV because of aggressive caching in DSR routes are already available so route discovery process occurs less often than AODV. In AODV periodic Hello messages are exchanged which further increases routing overhead. DSDV and DSR exhibits almost same behavior in sparse networks but as network density increases DSR performance starts degrading. AODV and OLSR also seem to approach DSDV initially with network size of 20 nodes thereafter NRL increases to 8.69 from 0.42 in AODV and 5.46 from 0.68 in OLSR with fully dense networks.

Average end to end delay increases as network size is increased from 20 to 100 nodes as packets spend more time waiting in interface queue for finding unexpired route to destination by the routing protocols. DSDV and OLSR being proactive protocols have lower delay than AODV and DSR. The delay time involves actual data delivery and initial route discovery time. Initially delay for DSR is less because of availability of routes in route cache but as congestion in the network increases due to more nodes, DSR control messages are lost thus routes are not established much fast. With smaller network sizes OLSR performs well but when size increases to 80 nodes AODV outperforms OLSR. In ZRP delay varies from $67.88 \mathrm{~ms}$ to $10652.82 \mathrm{~ms}$ as nodes vary from 20 to 100 . DSDV maintains almost consistent delay value with less effect of increasing nodes.

Table 4. Numerical comparison of Routing Protocols in terms of network density

\begin{tabular}{|l|c|c|c|c|c|}
\hline & DSDV & OLSR & AODV & DSR & ZRP \\
\hline Throughput & 4 & 2 & 1 & 3 & 5 \\
\hline PDF & 4 & 2 & 1 & 3 & 5 \\
\hline NRL & 1 & 2 & 4 & 2 & 5 \\
\hline E2E & 1 & 3 & 2 & 4 & 5 \\
\hline
\end{tabular}

\section{Effect of pause times}

Pause time is the time for which a node waits at a destination before moving to other destination within a specified simulation area. Keeping all other parameters constant, pause time is varied in to observe the behavior of performance metrics. The graphs show there is little effect of pause time on performance metrics as compared to other scenarios. Fig. 9 gives throughput comparison of different protocols. As pause time of a node increases PDF decreases initially and then starts increasing but up to a certain limit close to simulation time after which mobility is reduced to zero almost and nodes become stationery. Higher pause time means less mobility so more stable network is and fewer packets are lost. As pause time becomes $80 \mathrm{sec}$ PDF should increase more but it starts decreasing. The reason might be far placement of source and destination nodes. For smaller networks and low pause times DSR outperforms AODV so its PDF is highest and decrease is just $4.30 \%$ and for AODV decrease is $7.40 \%$. In DSR, multiple routes are available in route cache so fewer packets are dropped in case of high mobility but in AODV high mobility signifies more frequent link failures so more packet drops. DSDV shows worst performance. With low pause time DSDV 
delivered just $76 \%$ packets and with higher pause time it increases to $81.27 \%$. OLSR and ZRP also have PDF close to AODV with an average value of $96.16 \%$ and $93.91 \%$ respectively.

NRL decreases as pause time increases because of less frequent failures due to node's high mobility, route rediscovery messages are less as shown in Fig. 11. DSDV and DSR show consistent NRL with an average value of 0.15 and 0.20 respectively with varying pause time. NRL for DSR is comparatively less as compared to AODV because of aggressive caching characteristic of DSR. At pause time $10 \mathrm{sec}$, all the protocols have high routing loading because PDF is also low at $10 \mathrm{sec}$ due to loss of paths to some destination nodes due to bad placement of nodes and their movement patterns. In AODV as pause time decreases from 10 to $40 \mathrm{sec}$ NRL starts falling from 0.40 to 0.32 . ZRP shows worst performance. ZRP's performance is affected by certain other factors also like zone routing radius, cache mechanism where unused routes are kept and under saturated situations these routes can be deleted prematurely. It results in high NRL and high end to end delay. In order to improve ZRP performance, latest access time with every roué in routing table must be associated [19].

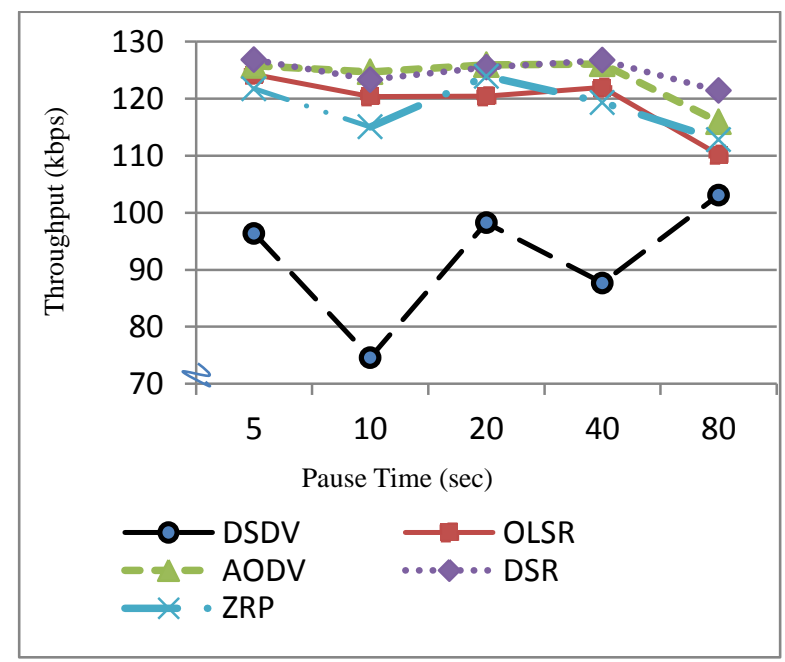

Fig.9. Throughput vs Pause Time

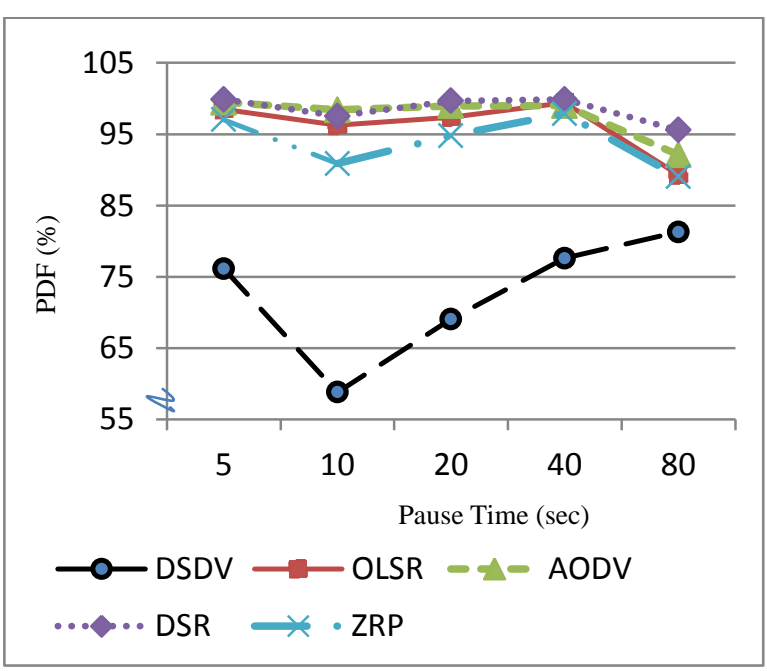

Fig.10. PDF vs Pause Time

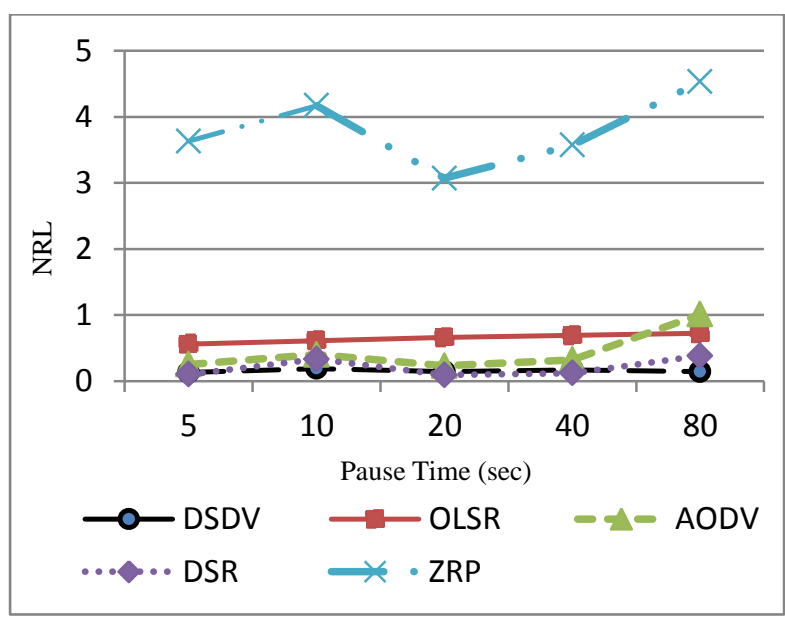

Fig.11. NRL vs Pause Time

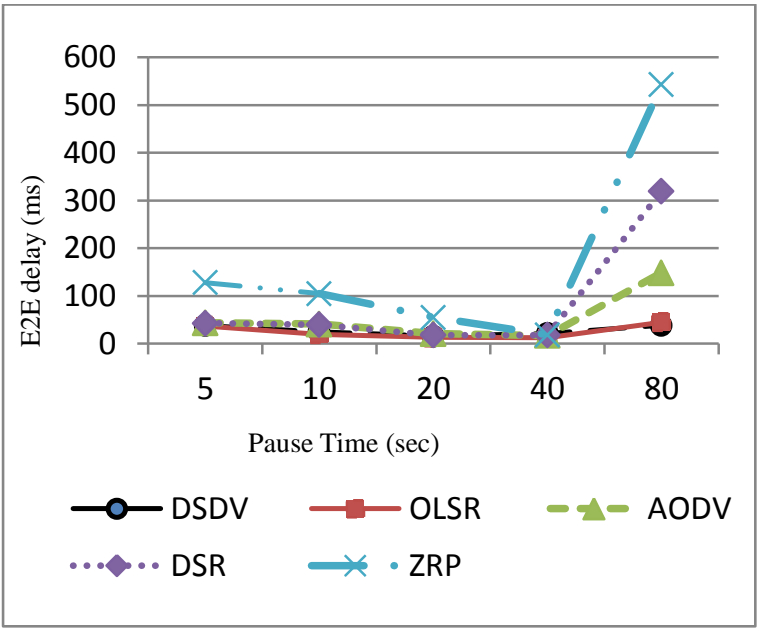

Fig.12. E2E delay vs Pause Time

With increasing pause time and lowering node mobility end to end delay decreases because of less link failures as shown in Fig. 12. DSDV and OLSR show consistent delay with an average value of $27.54 \mathrm{~ms}$ and $25.04 \mathrm{~ms}$ respectively. AODV occupies third best performance. ZRP involves combination of three other protocols IARP, IERP and BRP and their effectiveness depends on zone radius. In this paper we fixed zone radius of 2. Replacing IARP and IERP with some proactive and reactive protocols might result in improving ZRP's performance. The use of link state routing within zones helps in improving end to end delay [20].

Table 5. Numerical comparison of Routing Protocols in terms of pause time

\begin{tabular}{|c|c|c|c|c|c|}
\hline & DSDV & OLSR & AODV & DSR & ZRP \\
\hline Throughput & 5 & 3 & 1 & 2 & 4 \\
\hline PDF & 5 & 3 & 2 & 1 & 4 \\
\hline NRL & 1 & 4 & 3 & 2 & 5 \\
\hline E2E & 2 & 1 & 3 & 4 & 5 \\
\hline
\end{tabular}


Table 6. Overall ranking of routing protocols

\begin{tabular}{|c|l|}
\hline Throughput & AODV $>$ DSR $>$ OLSR $>$ ZRP $>$ DSDV \\
\hline PDF & DSR $>$ AODV $>$ OLSR $>$ ZRP $>$ DSDV \\
\hline NRL & DSDV $>$ DSR $>$ OLSR $>$ AODV $>$ ZRP \\
\hline E2E Delay & DSDV $>$ OLSR $>$ AODV $>$ DSR $>$ ZRP \\
\hline
\end{tabular}

\section{CONCLUSION}

In this paper, we compared performance of five MANET routing protocols in three different scenarios varying number of nodes, speed of nodes and their pause time. In all the scenarios, reactive protocols outperforms proactive in terms of throughput and PDF whereas proactive protocols outperforms in terms of E2E delay and NRL. AODV showed the best overall performance and after that DSR and OLSR, DSDV exhibited average performance and ZRP worst. Table 6 gives relative ranking of MANET routing protocols in context of various performance metrics evaluated above.

While varying speed and pause time for smaller networks DSR maintained high packet delivery fraction. Being on-demand protocol, there is always a chance of fresh and active route to be selected so fewer packets are dropped. But this on-demand route discovery causes more routing packets in the network and slightly more end to end delay due to more link breaks. Increasing speed not only leads to more packets drops but also increases NRL and delay.

DSR performs better in small networks and as density increases it fails and due to formation of temporary loops it shows high delay. The degradation in performance of DSR as compared to AODV is due its inability to expire stale routes so for denser networks AODV is more effective. AODV and DSR perform better than DSDV in high mobility scenarios because high mobility leads to frequent link failures and the larger overhead is involved in updating routing tables of all the nodes with this new routing information. ZRP can be more effectively used by selecting optimum zone radius, cache mechanism and precise query node having good battery and processing power. In future, extensive simulations can be performed to provide better insight of ad hoc network routing protocols.

\section{REFERENCES}

[1] Bouhorma, M., Bentaouit, H. and Boudhir, A. (2009) 'Performance Comparison of Ad-hoc Routing Protocols AODV and DSR', IEEE, International Conference on Multimedia Computing and Systems, October 2009, pp. 511-514.

[2] Jayakumar, G. and Ganapathy G. (2007) 'Performance Comparison of Mobile Ad-hoc Network Routing Protocol', International Journal of Computer Science and Network Security (IJCSNS), Vol.7 No.11, pp. 77-84.

[3] Tamilarasan S., (2012) 'A Quantitative Study and Comparison of AODV, OLSR and TORA Routing Protocols in MANET', International Journal of Computer
Science Issues (IJCSI), Vol. 9, No. 1, pp. 364-369.

[4] Kaur, D., \& Kumar, N., (2013) 'Comparative Analysis of AODV, OLSR, TORA, DSR and DSDV Routing Protocols in Mobile Ad-Hoc Networks', International Journal of Computer Network and Information Security (IJCNIS), Vol. 5, No. 3, pp. 39-46.

[5] Kumar, A., Singh, P., Kumar, V., \& Tyagi, N., (2013) 'Performance Analysis of AODV, CBRP, DSDV and DSR MANET Routing Protocol using NS2 Simulation', International Journal of Computer Network and Information Security (IJCNIS), Vol. 5, No. 9, pp. 45-50.

[6] Bansal, P., \& Thakur, J, (2014) 'Performance Analysis of AODV, DSR and CGSR Routing Protocol in MANET based on Energy Consumption', Journal of Network Security, Vol. 2, No. 1, pp. 21-27.

[7] Jha, R. K., \& Kharga, P, (2015) 'A Comparative Performance Analysis of Routing Protocols in MANET using NS3 Simulator', Vol. 4, pp. 62-68.

[8] Perkins C. E. and Bhagwat, P. (1994) 'Highly Dynamic Destination-Sequenced Distance-Vector (DSDV) for Mobile Computers', Proc. ACM Conf. Communications Architectures and Protocols, London, UK, August 1994, pp. 234-244.

[9] Clausen, T., Jacquet, P., Laouiti, A., Muhlethaler, P., Qayyum, A. and Viennot, L. (2001) 'Optimized link state routing protocol for ad hoc networks', In Proceedings of IEEE INMIC, December 2001, pp. 62-68.

[10] Clausen, T., Dearlove, C., Jacquet, P. (2008) 'The Optimized Link State Routing Protocol version 2', MANET Working Group, Available: http://www.ietf.org/internetdrafts/draft-ietf-manet-olsrv205.txt, February 2008.

[11] Laouiti, A., Qayyum, A. and Viennot, L. (2002) 'Multipoint Relaying: An Efficient Technique for Flooding in Mobile Wireless Networks', In Proceedings of the $35^{\text {th }}$ Annual Hawaii International Conference On System Sciences (HICSS' 2002). Waikoloa, HI, January 2002.

[12] Perkins, C., Royer, E. and Das, S. (2003) Ad hoc OnDemand Distance Vector (AODV) Routing. IETF, RFC 3561, 2003.

[13] Bhatia, T., \& Verma, A. K. (2013) 'Performance Evaluation of AODV under Blackhole Attack', International Journal of Computer Network and Information Security (IJCNIS), Vol. 5, No. 12, pp. 35-44.

[14] Johnson, D. B., Maltz, D. A. and Broch, J. (2001) 'DSR: The Dynamic Source Routing Protocol for Multi-Hop Wireless Ad hoc Networks', Ad Hoc Networking, C.E. Perkins, Ed., Addison-Wesley, 2001, pp. 139-172.

[15] Gupta, A. K., Sadawarti H. and Verma, A.K. (2010) 'Performance analysis of AODV, DSR \& TORA Routing Protocols', IACSIT International Journal of Engineering and Technology, Vol.2, No.2, pp. $226-331$.

[16] Haas, Z.J., Pearlman, M.R., Samar, P., (2002) 'The Zone Routing Protocol (ZRP) for Ad Hoc Networks', IETF Internet Draft, draft-ietf-manet-zone-zrp-04.txt, July 2002.

[17] Samar, P., Pearlman, M. R. and Haas, Z. J., (2004) 'Independent zone routing: an adaptive hybrid routing framework for ad hoc wireless networks', IEEE/ACM Transactions on Networking (TON), Vol. 12, pp. 595-608.

[18] Salleh, A. U., Ishak, Z., Muhammad, N. and Jamaludin. M. D, (2006) 'Trace Analyzer for NS-2', IEEE, Student Conference on Research and Development (SCOReD), Malaysia, 2006, pp. 29-32.

[19] Tabash, I. K., Ahmad, N. and Beg, S., (2010) 'Performance Evaluation of TCP Reno and Vegas over different routing protocols for MANETs', IEEE 4th 
International Symposium on Advanced Networks and Telecommunication Systems, IEEE Xplore, pp. 82-84.

[20] Mallapur, S. V. and Terdal, S., (2010) 'Enhance Ad-Hoc on Demand Multipath Distance Vector Routing Potocol (EAOMDV)', International Journal of Computer Science and Information Security, Vol. 7, No. 3, pp.166-170.

[21] Issariyakul, T, and Hossain, E. (2009) 'Introduction to Network Simulator NS2', Springer, US 2009.

[22] Bakalis, P. and Lawal, B. (2010) 'Performance Evaluation of CBR and TCP Traffic Models on MANET Using DSR Routing Protocol', Communications and Mobile Computing (CMC), International Conference on, 2010, Vol. 3, pp. 318-322.

[23] Navidi, W. and Camp, T. (2004) 'Stationary distributions for the random waypoint mobility model', IEEE Trans. Mob. Comp., Vol. 3 No. 1, pp. 99-108.

[24] Li, H., Qiu, F. and Liu Y., (2007) 'Research on Mechanism Optimization of ZRP Cache Information Processing in Mobile Ad Hoc Network', Wireless Communications, Networking and Mobile Computing, 2007. WiCom 2007. International Conference on, pp.1593-1596, 21-25 Sept. 2007.

[25] Sulaiman, T.H., Al-Raweshidy, H.S., (2006) 'Centralised Link-State Routing in ZRP', Personal, Indoor and Mobile Radio Communications, 2006 IEEE 17th International Symposium on, 11-14 Sept. 2006, pp. 1-5.

\section{Authors' Profiles}

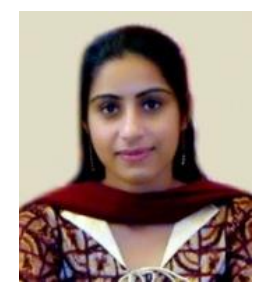

Tarunpreet Bhatia is currently working as lecturer in CSED at Thapar University, Patiala. She received her B. Tech from ACE, Kurukshetra University and M.E. from Thapar University, majoring in Computer science and engineering. She has published many papers in referred journals and conferences (India and Abroad). Her research interests include wireless networks, routing, network security and cloud computing.

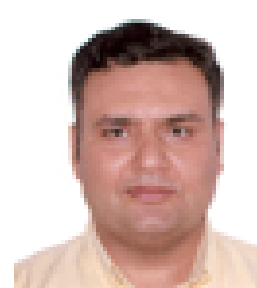

Dr. A. K. Verma is currently an Associate Professor in the department of Computer Science and Engineering at Thapar University, Patiala. He received his B.S., M.S. and Doctorate in 1991, 2001 and 2008, respectively, majoring in Computer science and engineering. He has worked as Lecturer at M.M.M. Engineering College, Gorakhpur from 1991 to 1996. He joined Thapar University in 1996. He has published over 120 papers in referred journals and conferences (India and Abroad). He has chaired various sessions in the International and National Conferences. He is a MIEEE, MACM, MISCI, LMCSI, MIETE, GMAIMA. He is a certified software quality auditor by MoCIT, Govt. of India. His research interests include wireless networks, routing algorithms and cloud computing.

How to cite this paper: Tarunpreet Bhatia, A.K. Verma,"QoS Comparison of MANET Routing Protocols", IJCNIS, vol.7, no.9, pp. 64-73, 2015.DOI: 10.5815/ijcnis.2015.09.08 